\title{
Decoupled phytoplankton growth and microzooplankton grazing in the deep euphotic zone of the eastern equatorial Pacific
}

\author{
Michael R. Landry ${ }^{1, *}$, Karen E. Selph ${ }^{2}$, Eun Jin Yang ${ }^{3}$ \\ ${ }^{1}$ Scripps Institution of Oceanography, University of California at San Diego, La Jolla California 92093-0227, USA \\ ${ }^{2}$ Department of Oceanography, University of Hawaii at Manoa, Honolulu, Hawaii 96822, USA \\ ${ }^{3}$ Division of Polar Climate Research, Korea Polar Research Institute, KORDI, Songdo Techno Park, Songdo, Yeonsu, \\ Incheon 406-840, South Korea
}

\begin{abstract}
We conducted dilution depth-profile experiments in the eastern equatorial Pacific (EEP) to define regional characteristics of phytoplankton growth and microzooplankton grazing and to test the hypothesis that the process rates decouple in the deep euphotic zone where growth is negligible. We used an abbreviated 2-treatment dilution protocol to produce daily profiles at 8 depths of phytoplankton growth, microzooplankton grazing and cellular changes in chlorophyll a (chl a) content from surface waters to the $0.1 \%$ light depth. Experiments were conducted at 16 stations from $2^{\circ} \mathrm{N}$ to $4^{\circ} \mathrm{S}$ at $110^{\circ} \mathrm{W}$ and from $110^{\circ}$ to $140^{\circ} \mathrm{W}$ along the equator. Results were surprisingly robust and coherent over this broad spatial area and showed a euphotic zone essentially divided into 3 equal depth intervals. Mean $( \pm \mathrm{SD})$ growth rates $\left(0.83 \pm 0.16 \mathrm{~d}^{-1}\right)$ exceeded grazing rates $\left(0.42 \pm 0.15 \mathrm{~d}^{-1}\right)$ in the light-saturated upper third of the water column. Growth, and to a lesser extent grazing, declined with light in the middle third. Effective cell growth was negligible $\left(0.02 \pm 0.21 \mathrm{~d}^{-1}\right)$ in the lower third (1 to $0.1 \%$ of surface irradiance), with grazing $\left(0.18 \pm 0.17 \mathrm{~d}^{-1}\right)$ exceeding growth in this layer. The deep euphotic zone accounted for $25.4 \pm 8.4 \%$ of the total euphotic zone chl $a, 0.5 \pm 7.8 \%$ of depth-integrated phytoplankton growth and $12.7 \pm 7.2 \%$ of depth-integrated microzooplankton grazing on phytoplankton. The decoupling of growth and grazing processes under low light conditions at the base of the euphotic zone substantially affected our estimates of microzooplankton consumption of phytoplankton, which ranged from $51 \%$ of daily chlorophyll growth for experiments conducted in the upper euphotic zone to $69 \%$ for the depth-integrated euphotic zone. In addition, the excess of grazing over growth processes in the deepest stratum, which is typically overlooked in experimental studies, suggests that protistan grazers may have a much larger role in biogeochemical transformations of export fluxes than previously appreciated.
\end{abstract}

KEY WORDS: Microzooplankton grazing $\cdot$ Phytoplankton growth rate $\cdot$ Lower euphotic zone Equatorial Pacific

- Resale or republication not permitted without written consent of the publisher

\section{INTRODUCTION}

Recent efforts to synthesize our understanding of phytoplankton growth, microzooplankton grazing and their rate relationships and implications from dilution experiments have demonstrated general patterns that relate to ocean habitat type and system trophic richness (Calbet \& Landry 2004, Landry \& Calbet 2004).
However, the relatively modest database of $<800$ experiments generated by 66 studies over 2 decades has also highlighted areas in which that understanding is quite deficient. Few ocean provinces, for example, are covered with adequate data density to define their mean characteristics or to compare and contrast meaningfully the systems in time or space. The number of independent experiments per study is typically small, 
12 on average, and methodological variations among investigators can make direct comparisons difficult. The total database is also heavily biased toward rate estimates from the upper mixed layer. At deeper depths in the euphotic zone, the frequency of estimates is greatly diminished.

The present study was designed to elucidate regional characteristics in the coupling of growth and grazing processes with depth in the eastern equatorial Pacific (EEP). The EEP is a region with an open-ocean upwelling and high nutrient, low chlorophyll (HNLC) content and is globally significant as the largest natural source of $\mathrm{CO}_{2}$ released to the atmosphere (Feely et al. 2002). It is also a system of relative biological and chemical constancy that is said to function in many respects like a nutrient-limited and grazer-regulated chemostat (Frost \& Franzen 1992, Landry et al. 1997, Dugdale \& Wilkerson 1998, Dugdale et al. 2007). It is thus an interesting region in which to explore variability and rate relationships in experiments that can be repeated many times over an extensive geographical area. In the present study, we use an abbreviated, 2treatment dilution experimental protocol to produce daily profiles at 8 depths of phytoplankton growth, microzooplankton grazing and cellular changes in chlorophyll content from surface waters to the $0.1 \%$ light depth. In particular, we test the hypothesis that microzooplankton grazing rate is significant in the deep euphotic zone where substantial phytoplankton chlorophyll a (chl a) is present, but phytoplankton growth is negligible. From our results, the decoupling of growth and grazing at the base of euphotic zone could be a feature of many systems that could lead to underestimates of microzooplankton grazing roles in the oceans, including their potential to transform the export rain of phytoplankton cells and other particulates from surface to deeper waters.

\section{MATERIALS AND METHODS}

Experimental set-up. Experimental studies of phytoplankton growth and microzooplankton grazing were conducted in the EEP between 110 and $140^{\circ} \mathrm{W}$ on a December 2004 cruise of the RV 'Roger Revelle'. At each of the 16 stations (Fig. 1), we conducted a profile of incubation experiments at 8 depths. Water was collected in a predawn (typically 03:00 h) CTD cast at the near surface (1 to $2 \mathrm{~m}$ ) and at depths corresponding to $52,31,13,7.6,5.0,0.8$ and $0.1 \%$ of surface irradiance. Because these samples were taken during nighttime (dark) hours, corresponding light depths were computed from an empirical relationship between beam transmisson $(630 \mathrm{~nm})$ and photosynthetically active radiation (PAR) diffuse attenuation taken from the pre- ceding mid-day CTD casts (Balch et al. 2011). Among stations in the north-south transect at $110^{\circ} \mathrm{W}$ (Stns 3 to $9)$, the depth of the euphotic zone, as defined by $0.1 \%$ surface light penetration ( $\left.\% I_{0}\right)$, varied from 120 to $131 \mathrm{~m}$. Among stations in the east-west equatorial transect to the west of $110^{\circ} \mathrm{W}$ (Stns 11 to 19), the euphotic zone varied from 96 to $112 \mathrm{~m}$.

The basic experimental design followed the 2treatment dilution approach of Landry et al. (1984), as adapted to shipboard use by Landry et al. (2008). For the water collected at each sampling depth, we prepared a pair of 2.71 polycarbonate bottles containing unfiltered seawater $(100 \%)$ and a mixture of $37 \%$ whole seawater diluted with $0.1 \mu \mathrm{m}$ filtered seawater from the same sampling depth. The seawater was filtered directly from the Niskin bottles, in which water samples were collected, by means of a peristaltic pump, silicone tubing and an in-line Suporcap filter capsule that had previously been acid washed $(10 \%$ trace-metal grade $\mathrm{HCl}$ followed by Milli-Q and seawater rinses). Dilution treatment bottles received premeasured volumes of filtered water from the collection depths, then both diluted and whole seawater treatments were gently filled (silicone tubing was placed below the water level) with unscreened water from the Niskin bottles, alternating the flow into each bottle until they were both topped off at about the same time. Each bottle was subsampled for flow cytometric analysis to confirm initial concentrations and volume dilutions. The bottles were then tightly capped, placed in pairs into their respective incubators, which were screened with neutral density plastic film (Cotech) to achieve the relative light levels $\left(\% I_{0}\right)$ at the depths of sample collection. Experiments were initiated before sunrise; the total elapsed time from Niskin sampling to the incubator took about $1.5 \mathrm{~h}$. Final samples were taken 24 h later. All incubators were cooled with surface seawater, which averaged $24.9 \pm 0.6^{\circ} \mathrm{C}$ from all stations. With few exceptions, the decline in temperature with depth was relatively modest above the $0.8 \%$ light depth, which had a mean temperature of $22.2 \pm$

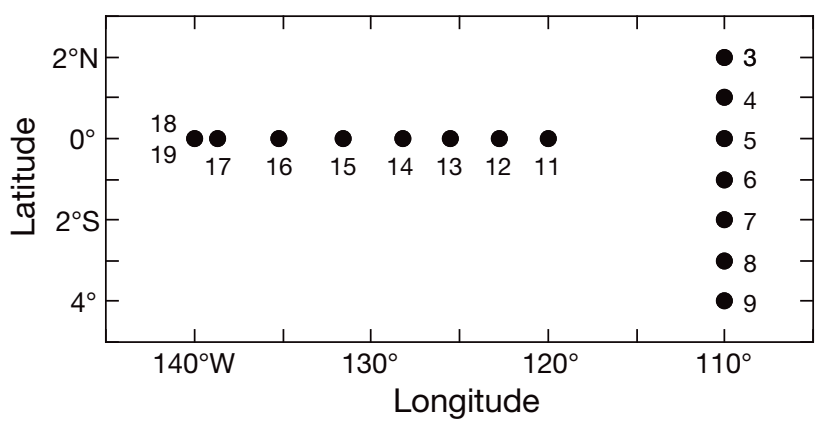

Fig. 1. Locations of experimental stations in the equatorial region of the Pacific Ocean 
$3.3^{\circ} \mathrm{C}$. Below that, ambient temperature decreased more sharply to $18.2 \pm 3.9^{\circ} \mathrm{C}$ at the depth of $0.1 \% I_{0}$. Rate estimates from incubations of the deepest samples may therefore be temperature enhanced above in situ rates.

To test the linearity assumptions of the dilution method (Landry \& Hassett 1982), we also conducted standard, multitreatment dilution experiments at select sites according to the protocols of Landry et al. (1998). These experiments were started with water collected at the 31 and $7.6 \%$ light depths from late afternoon CTD casts. Replicated dilution treatments of $0.22,0.45$, $0.65,0.86$ and 1.0 times natural seawater were prepared in 2.21 polycarbonate bottles as described above, by adding measured aliquots of filtered water first. Each of these dilution treatment bottles received added nutrients (final concentrations of $0.5 \mu \mathrm{M} \mathrm{N}$ ammonium, $0.1 \mu \mathrm{M}$ manganese, $0.03 \mu \mathrm{M}$ phosphate and $1.0 \mathrm{nM} \mathrm{FeSO} 4)$ to promote constant phytoplankton growth. Two additional bottles were also prepared as replicate control bottles for incubation without added nutrients. Each of these bottles was filled to capacity with natural unscreened seawater from the depth of collection, which came from a mixing carboy that was filled gently via submerged tubing from the contents of several rosette bottles. All experimental bottles were incubated for $24 \mathrm{~h}$, starting at 18:00 h local time (around sunset), in the appropriately screened deck incubators. These dilution experiments thus differed from the 2-bottle experiments in the time of day at which they were started (dark-to-light versus light-todark portions of the daily photocycle), in the number of dilution treatments, in treatment replication and in the use of nutrient additions.

Phytoplankton analyses. Samples were taken for chl $a$ and flow cytometric (FCM) analyses at the start and end of each experiment to determine initial abundances and dilution concentrations and to assess the rates of growth and grazing losses in the dilution incubations. Samples $(520 \mathrm{ml})$ for chl a analyses were filtered onto $25 \mathrm{~mm} \mathrm{GF/F}$ filters (Gelman) and extracted in $10 \mathrm{ml}$ of $90 \%$ acetone for $24 \mathrm{~h}$ at $-20^{\circ} \mathrm{C}$. Fluorometric analyses of chl a were made with a fluorometer (model TD-700, Turner Designs) with equations calibrated against a pure chl a standard.

Cell abundances of eukaryotic phytoplankton were determined on board the ship from FCM analyses of unpreserved $50 \mathrm{ml}$ samples within 1 to $3 \mathrm{~h}$ of collection. For these analyses, we used a cytometer (model XL, Beckman-Coulter) equipped with a $15 \mathrm{~mW}, 488 \mathrm{~nm}$, argon ion laser and an Orion syringe pump for quantitative sample delivery (Selph et al. 2001). Phytoplankton cells were distinguished on the basis of light scatter (forward and $90^{\circ}$ side scatter), chl a (red fluorescence, $680 \mathrm{~nm}$ ) and phycoerythrin (orange fluorescence,
$575 \mathrm{~nm})$. Fluorescent calibration beads of $6 \mu \mathrm{m}$ were used in all samples as an internal standard to normalize the data.

Cell abundances and fluorescence characteristics of prokaryotic picoplankton (Prochlorococcus, Synechococcus) were determined using a shore-based flow cytometer. These samples $(2 \mathrm{ml})$ were preserved with paraformaldehyde $(0.5 \%$, v/v, final concentration, $)$, frozen in liquid nitrogen at sea and subsequently transferred to a $-80^{\circ} \mathrm{C}$ freezer for storage until analysis. Batches of samples were stained with Hoechst 33342 (1 $\mu \mathrm{g} \mathrm{ml}^{-1}, \mathrm{v} / \mathrm{v}$, final concentration) and incubated at room temperature in the dark for $1 \mathrm{~h}$ before analysis (Campbell \& Vaulot 1993, Monger \& Landry 1993). Aliquots $(100 \mu l)$ were analyzed using a cytometer (model EPICS Altra, Beckman-Coulter) with a Harvard Apparatus syringe pump for volumetric sample delivery. Simultaneous (colinear) excitation of the plankton was provided by 2 argon ion lasers, tuned to $488 \mathrm{~nm}(1 \mathrm{~W})$ and the UV range $(200 \mathrm{~mW})$. The optical filter configuration was similar to that described above for the shipboard cytometer, with the addition of a detector for DNA (blue fluorescence, $450 \mathrm{~nm}$ ). Calibration beads ( 0.5 and $1.0 \mu \mathrm{m}$ yellow-green beads and $0.5 \mu \mathrm{m}$ UV beads) were used to standardize fluorescence and scatter parameters. Raw data (listmode files) from both instruments were processed using the software FlowJo (Treestar, www.flowjo.com).

For the present analysis, we used flow cytometric results principally to account for cellular changes in chl $a$ of the 2 dominant groups of photosynthetic organisms, Prochlorococcus and eukaryotic algae, in the equatorial region. For each category, FCM analyses provided initial (i) and final ( $f$ ) estimates of beadnormalized chl a red fluorescence per cell (Fl), from which daily instantaneous rates of change for the $24 \mathrm{~h}$ incubations were computed as $\ln \left(\mathrm{Fl}_{f} / \mathrm{Fl}_{i}\right)$. These calculations were made for each pair of initial and final subsamples from individual experiments and applied to each experiment in proportion to the ratios of divinyl chl a (Prochlococcus) and monovinyl chl a (eukaryotes) to total chl a as described by Selph et al. (2011). Synechococcus comprised a small component, $\sim 7 \%$, of phytoplankton biomass (Taylor et al. 2011).

Growth and grazing estimates. Instantaneous rates of phytoplankton growth $(\mu)$ and mortality losses $(m)$ to microzooplankton grazing were estimated from dilution incubations according to Landry et al. (1998) for standard multitreatment experiments and Landry et al. (2008) for the 2-treatment depth profiles. For the latter, the net rate of change $(k)$ of chl $a$ in the undiluted treatment is $k=\mu-m$. Assuming similar growth rate $(\mu)$ in the diluted treatment, the net rate of change $k_{\mathrm{d}}=\mu-x \times m$, where $x$ is the fraction of natural grazer density in the diluted treatment $(0.37$ in these experi- 
ments). From measured differences in the net rates of population change in the 2 treatments, the 2 equations were solved for the 2 unknowns, $\mu$ and $m$.

$$
m=\left(k_{\mathrm{d}}-k\right) /(1-0.37) \text { and } \mu=k+m
$$

Net growth rate $(k)$ estimates exceeded $k_{\mathrm{d}}$ on 5 occasions in our 128 experiments, mostly in samples from the deep euphotic zone. The mean difference $\left(-0.03 \mathrm{~d}^{-1}\right)$ was very slight and not different from a result of zero grazing. We chose not to adjust these slightly negative grazing rate estimates to zero in our data on the assumption that there were compensatory errors on the positive side to balance them out. In all respects, therefore, the calculated rates from the above equations reflect exactly the shipboard fluorometric readings.

\section{RESULTS}

\section{Raw rate estimates}

The results of our fluorometric analyses of chl a are shown in Fig. 2. Ambient concentrations of chl a (i.e. initial concentrations for the dilution experiments) were indicative of the HNLC condition in the EEP and varied generally between 0.1 and $0.3 \mu \mathrm{g} \mathrm{chl} \mathrm{a} \mathrm{l}^{-1}$ throughout the euphotic zone. The mean depth profile is relatively featureless, averaging slightly in excess of $0.2 \mu \mathrm{g}$ chl a $\mathrm{l}^{-1}$ with a very modest subsurface peak declining gradually to $\sim 0.1 \mu \mathrm{g} \mathrm{chl} \mathrm{a} \mathrm{l}^{-1}$ at the depth of $0.1 \%$ surface light. Stations on the north-south transect at $110^{\circ} \mathrm{W}$, particularly those on the southern end of the line (Stns 8 and 9) tended to be on the lower side of the average chl a profile, while stations on the western side of the equatorial transect typically had values higher than average. Nonetheless, the relative uniformity of the chl a standing stock is more remarkable than the variability observed, given the large spatial area sampled.

Similarly, what stands out in the plots of the growth and grazing rate estimates is a depth pattern that is repeated with only modest station variability (Fig. 2). Growth rates show a near-surface minimum rising sharply to a subsurface maximum of $\sim 1.2 \mathrm{~d}^{-1}$ on average in the upper euphotic zone and declining to zero at the $1 \%$ light level. In contrast, grazing rate estimates display a more subtle profile, averaging $\sim 0.4 \mathrm{~d}^{-1}$ in the upper euphotic zone and declining to about half that at the deepest depths sampled. Each of the rate estimates in Fig. 2 is derived from one unreplicated pair of incubation bottles initiated independently (i.e. different collection depths, days or locations) of all others. The relative uniformity of growth environment conditions indicates that they relate to one another in a way that conveys a strong pattern rather than one of random variability and noise.
Based on the mean profiles for growth and grazing rates (Fig. 3), the euphotic zone of the EEP is roughly divided into 3 approximately equal depth strata based on light penetration. The highest rates of phytoplankton growth and microzooplankton grazing occur in the upper euphotic zone, which is defined from the surface to $\sim 10 \%$ light depth. Light appears to be saturating for maximal growth within this stratum, which corresponded approximately to the upper mixed layer during our study. The drop-off in growth near the surface should be considered a bottle artifact, a consequence of exposing water samples contained in bottles to unfiltered equatorial sunshine for a full day as opposed to having them circulate freely in the mixed layer, as ambient plankton would do. Between the 10 and $1 \%$ light levels, growth rate drops off in log-linear fashion with declining light while grazing declines by about half. In the deepest third of the euphotic zone, between 1 and $0.1 \%$ surface light, there is, on average, little net phytoplankton cell growth or even a slight negative rate (decomposition, degradation) at the maximum depth of sampling. Since microzooplankton grazing does not decline to zero in this depth range, the deep euphotic zone is also a stratum where grazing losses significantly exceed phytoplankton growth.

Because all incubations were done at surface seawater temperature (SST), rate determinations for deepcollected samples probably overestimate, on average, what they are at ambient temperature. For samples from $0.1 \% I_{0}$, the difference between SST and temperatures at depth varied from 0.1 to $11^{\circ} \mathrm{C}$. As shown in Fig. 4, rate estimates for both growth and grazing tended to increase at stations where this temperature differential was higher, though neither trend was statistically significant. More importantly, there was no effect of this temperature difference on mean estimates of the excess of grazing over growth $(m-\mu)$ at depth.

Although individual experiments were unreplicated in our design, we can derive some estimates of regional variability and experimental precision from the resulting data. Excluding the surface incubations, where more variable results presumably derive from day-to-day variability in cloud cover and photo-damage to the contained mixed-layer phytoplankton, SDs for all experiments conducted in the upper euphotic zone (i.e. 13 to $52 \%$ of surface irradiance) averaged $0.12 \mathrm{~d}^{-1}$ for growth and $0.15 \mathrm{~d}^{-1}$ for grazing rates. These reflect the reproducibility of results at different locations in the study region. To assess the likely precision of the method for experiments conducted with water of similar initial conditions, we used the 3 experiments conducted at each station in the zone of light-saturated growth as replicates. Mean SDs from this within-station analysis were $0.07 \mathrm{~d}^{-1}$ for growth and $0.11 \mathrm{~d}^{-1}$ for grazing rates. In both cases, withinstation variability was significantly lower than variabil- 

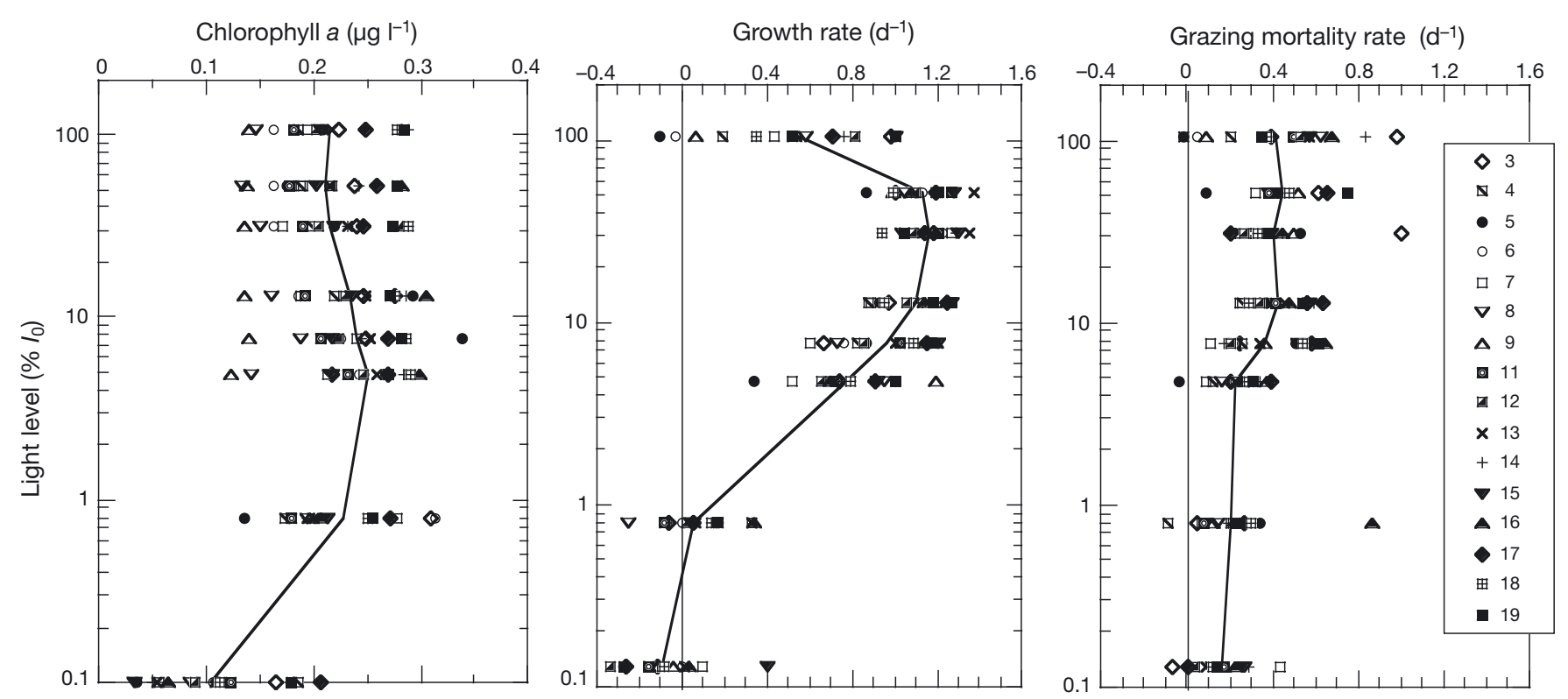

Fig. 2. Initial euphotic zone concentrations of chl $a$ and chlorophyll-based estimates of phytoplankton growth and microzooplankton grazing rates from dilution experiments in the equatorial Pacific region. Symbols refer to station numbers in Fig. 1. Lines show mean values as a function of the percent surface irradiance

ity between stations (ANOVA F-test: $\mathrm{p}<0.001$ for $\mu, \mathrm{p}=$ 0.03 for $m$ ). The station replicates differ, of course, in that they were collected at different depths and incubated at different light levels $(13,31$ and $52 \%$ light); thus, the within-station error estimates may be overstated. To the extent, however, that the upper layer was optimally mixed at the time of predawn sampling and the 3 light levels were each sufficient for maximal or near maximal growth, these error estimates provide a reasonable expectation of experimental precision for independently collected samples from the mixed layer in this region.

\section{Full dilution comparisons}

Experiments run at 110 and $140^{\circ} \mathrm{W}$ (Stns 5 and 18, respectively; Fig. 1) by the standard dilution protocol, with multiple dilution treatments and nutrients added, largely confirmed results from the 2-bottle approach (Fig. 5). The measured net rates of change of chl $a$ showed a linear response to the dilution manipulation, as expected from previous studies in the EEP (e.g. Landry et al. 1995a,b). Grazing rates determined from the linear regressions of the full dilution experiments $\left(0.41 \pm 0.12 \mathrm{~d}^{-1}\right)$ were essentially identical to mean estimates from the 2-treatment method in the light-depth range of 7 to $31 \% I_{0}\left(0.40 \pm 0.16 \mathrm{~d}^{-1}\right)$. Net growth rates of chl $a$ in no-nutrient treatments, shown as open diamonds in Fig. 5, were slightly lower, on average, that those in nutrient-added bottles, giving rise to lower estimates of phytoplankton growth rate (1.18 versus $1.27 \mathrm{~d}^{-1}$ at $31 \% I_{0} ; 0.89$ versus $0.84 \mathrm{~d}^{-1}$ at $7.6 \% I_{0}$ ). Both, however, are within one SD of growth rate estimates of $1.16 \pm 0.11 \mathrm{~d}^{-1}\left(31 \% I_{0}\right)$ and $0.96 \pm 0.20 \mathrm{~d}^{-1}\left(7.6 \% I_{0}\right)$ for the 2-bottle experiments at the same light depths. We conclude from this comparison that growth rate results from dilution experiments in the EEP are relatively insensitive to modest variations in technique (e.g. treatment number, with or without nutrient additions) or to beginning the $24 \mathrm{~h}$ incubations at dawn versus dusk. These experimental results are all compared based on uncorrected analysis of bulk chl $a$, the most commonly used proxy for phytoplankton biomass in dilution incubations.

\section{Changes in cellular chlorophyll content}

Using bead-normalized red fluorescence from flow cytometry as an index of change in cellular chlorophyll content (Fig. 6), it is evident that part of the increase in chl a bottles can be ascribed to a greening of cells rather than cell division. In addition, 2 major components of the autotrophic assemblage in equatorial waters, Prochlorococcus (PRO) and photosynthetic eukaryotes (P-Euk), show similar depth-dependent patterns in cellular response, but they differ in magnitude. PRO displayed little net adjustment of cellular pigment content in incubations at surface light intensities and at the deepest light depth $\left(0.1 \% I_{0}\right)$. However, cell chl $a$ increased for PRO in incubations at all intermediate euphotic depths, with a broad subsurface maximum growth rate of $\geq 0.2 \mathrm{~d}^{-1}$ between the 5 and $31 \%$ light depths. For eukaryotic algae, the rate of change of cell 


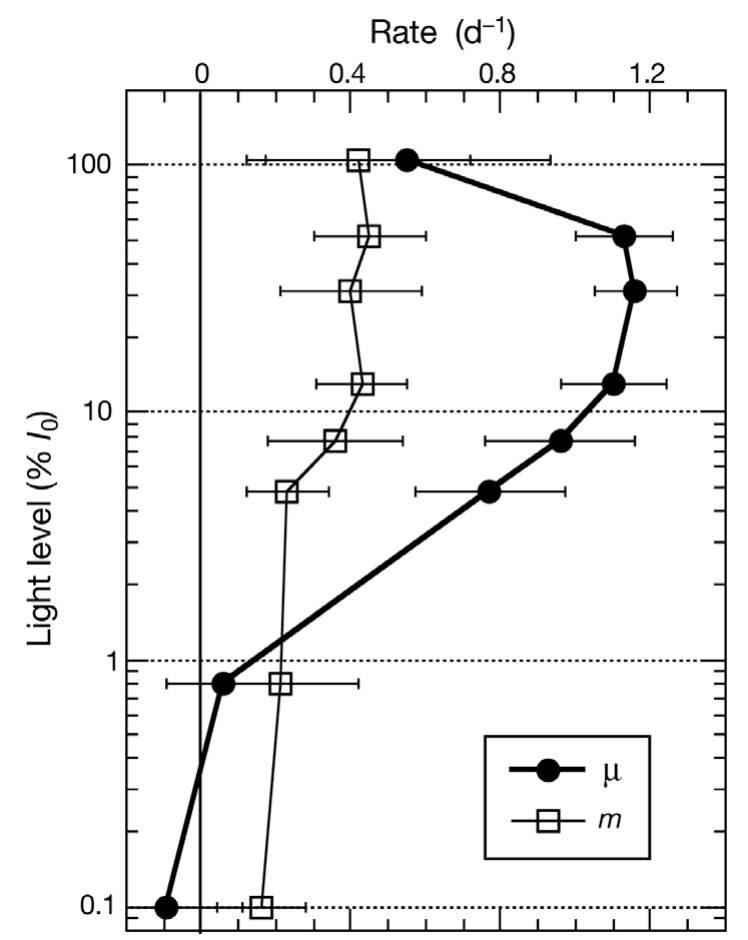

Fig. 3. Mean light-depth profiles for chlorophyll-based estimates of phytoplankton growth $(\mu)$ and microzooplankton grazing $(m)$ rates in the eastern equatorial Pacific. Error bars represent \pm SD for 2-bottle dilution experiments conducted at 16 stations. $I_{0}$ : surface irradiance

chl a content during the $24 \mathrm{~h}$ incubations increased approximately linearly from surface values of $0.1 \mathrm{~d}^{-1}$ to a maximum of $0.4 \mathrm{~d}^{-1}$ at the 31 and $13 \%$ light levels, and decreased below that to slightly negative rates $\left(-0.1 \mathrm{~d}^{-1}\right)$ in the deep euphotic zone below $1 \% I_{0}$.

\section{Growth and grazing rate profiles}

Fig. 7 shows the resultant mean depth profiles of instantaneous growth and grazing rates after changes in cellular chl a fluorescence (Fig. 6) are subtracted from raw growth estimates (Fig. 3). Fluorescence corrections were done separately for each experiment before averaging. The error bars in this case $(95 \%$ confidence limits [CL]) indicate that the numerous experiments in each depth horizon allowed us to define mean system characteristics within $95 \%$ CLs that are about half of the SD values. From these results, mixed-layer maximum growth rates of 0.8 to $0.9 \mathrm{~d}^{-1}$ decline to zero between the 1 and $0.1 \%$ light depths. Mean depthintegrated rate estimates $( \pm 95 \% \mathrm{CL})$, normalized to chl a concentration in the euphotic zone, are $0.41 \pm$ $0.08 \mathrm{~d}^{-1}$ for phytoplankton growth and $0.28 \pm 0.06 \mathrm{~d}^{-1}$ for microzooplankton grazing. Overall, microzooplankton consume $68.7 \pm 7.4 \%$ of the daily growth of
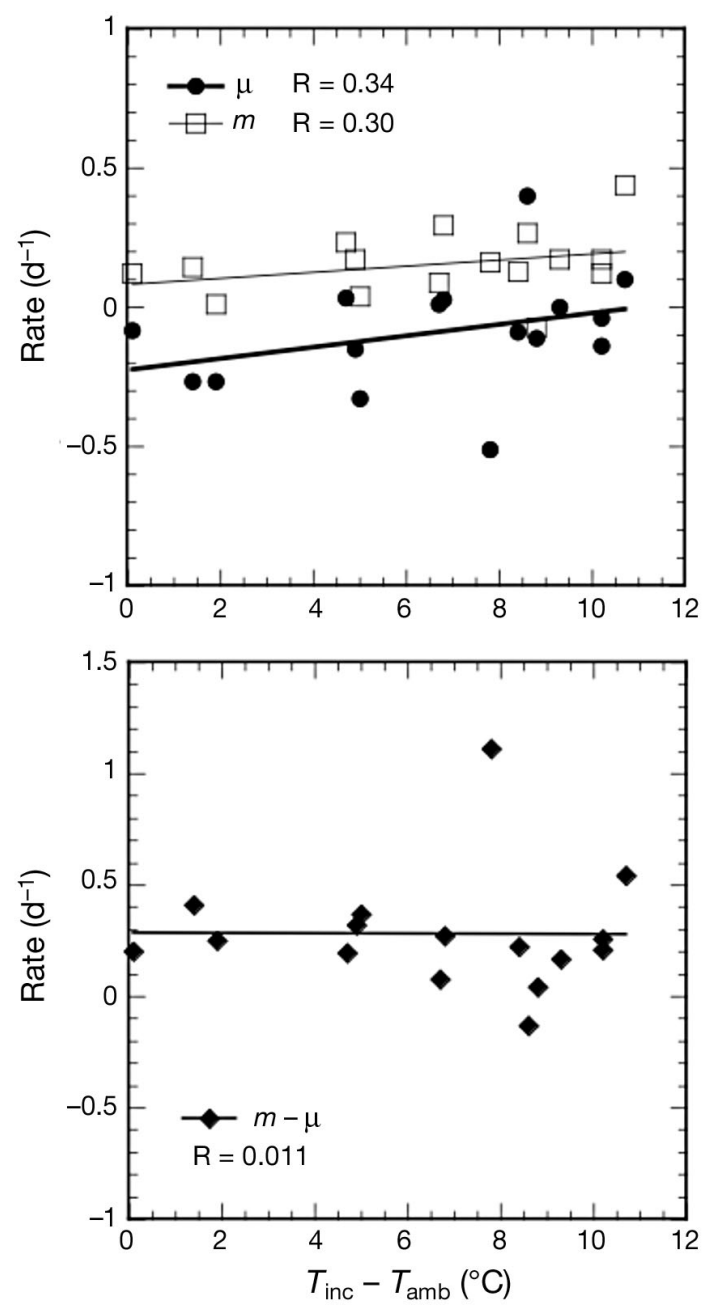

Fig. 4. Rate estimates of phytoplankton growth $(\mu)$ and microzooplankton grazing $(m)$ for the deep euphotic zone $\left(0.1 \% I_{0}\right.$ light depth) as a function of the temperature difference between surface seawater (incubation temperature, $T_{\text {inc }}$ ) and ambient temperature $T_{\mathrm{amb}}$ at depth of collection. $I_{0}$ : surface irradiance

the phytoplankton community (represented by chl a). However, growth exceeds grazing by about a factor of 2 in the upper mixed layer while grazing significantly exceeds growth in the deep euphotic zone (Fig. 7).

\section{DISCUSSION}

\section{Growth and grazing processes in the HNLC equatorial Pacific Ocean}

The results of the present study can be compared with previously conducted dilution studies of phytoplankton growth and microzooplankton grazing in the equatorial Pacific: 34 experiments conducted between 
$2^{\circ} \mathrm{N}$ and $2^{\circ} \mathrm{S}, 140^{\circ} \mathrm{W}$ on US Joint Global Ocean Flux Study (JGOFS) survey cruises in February-March and August-September 1992 (Landry et al. 1995a, Latasa et al. 1997); 15 experiments conducted at $0^{\circ}, 140^{\circ} \mathrm{W}$ on US JGOFS Equatorial Pacific (EqPac) time-series cruises in March-April and October 1992 (Verity et al. 1996); 13 experiments conducted between $5^{\circ} \mathrm{N}, 140^{\circ} \mathrm{W}$ and $8^{\circ} \mathrm{S}, 195^{\circ} \mathrm{W}$ on NOAA survey cruises from September to November 1992 (Chavez et al. 1996); 13 experiments conducted as part of the IronEx II fertilization study beginning at $4^{\circ} 40^{\prime} \mathrm{S}, 105^{\circ} \mathrm{W}$ in May 1995 (Landry et al. 2000b); and 8 experiments conducted at $3^{\circ} \mathrm{S}$ and $0^{\circ}, 180^{\circ}$ as part of the French JGOFS EBENE program in October and November 1996 (Landry et al. 2003). Among these 83 data points, $71 \%$ were from the upper level of high light (all incubated above $14 \% I_{0}$ ), $29 \%$ were from the midzone of intermediate light (1 to $8 \% I_{0}$ ) and none were from light depths $<1 \% I_{0}$. Relatively speaking, the equatorial Pacific is one of the best-characterized ocean regions where this methodol- ogy has been used, and is second only to the Arabian Sea among major ocean provinces (Landry 2009). Nonetheless, the present study more than doubles the total data for this region and provides significant new perspectives on depth-light dependent patterns and broad-scale spatial coherence.

Some of what has been known previously about dilution results from the equatorial Pacific is simply confirmed by the present study. For instance, net rates of change of phytoplankton respond to the dilution manipulation with good linearity in this region (Landry et al. 1995a, 2000b, Verity et al. 1996), and the linear relationship between grazing rate and dilution has also been tested there experimentally by means of fluorescently labeled tracer cells (Landry et al. 1995b). The few experiments that we have done with the traditional multitreatment dilution experiments illustrate this point (Fig. 5), which is an important assumption when applying the method in any system, and is especially critical for the 2-treatment approach used here.
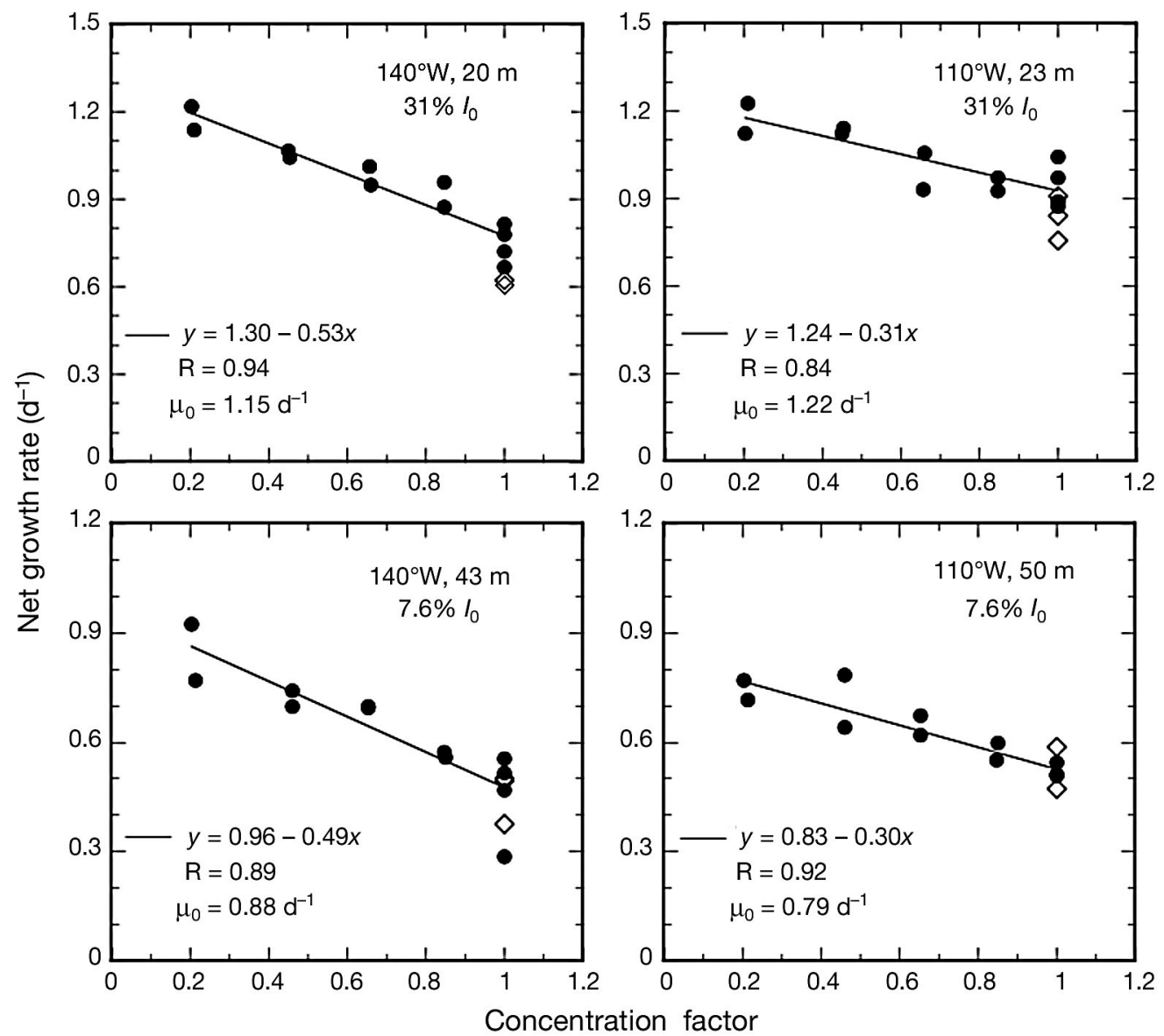

Fig. 5. Results of standard multitreatment dilution experiments conducted at 2 light levels (31 and $7.6 \%$ of surface irradiance, $I_{0}$ ) at $0^{\circ}, 110^{\circ} \mathrm{W}$ (Stn 5, Fig. 1) and $0^{\circ}, 140^{\circ} \mathrm{W}$ (Stn 18) in the equatorial Pacific region. For nutrient-amended treatments $\left({ }^{\circ}\right)$, regression equations give chlorophyll-based estimates of phytoplankton growth and microzooplankton grazing rates $\left(\mathrm{d}^{-1}\right)$ as the $y$-intercepts and slopes, respectively. $\diamond$ symbols are incubations without added nutrients. $\mu_{0}$ is the growth-rate estimate without added nutrients, calculated as the sum of regression slope $(m)+$ measured net growth rate of no-nutrient treatments 


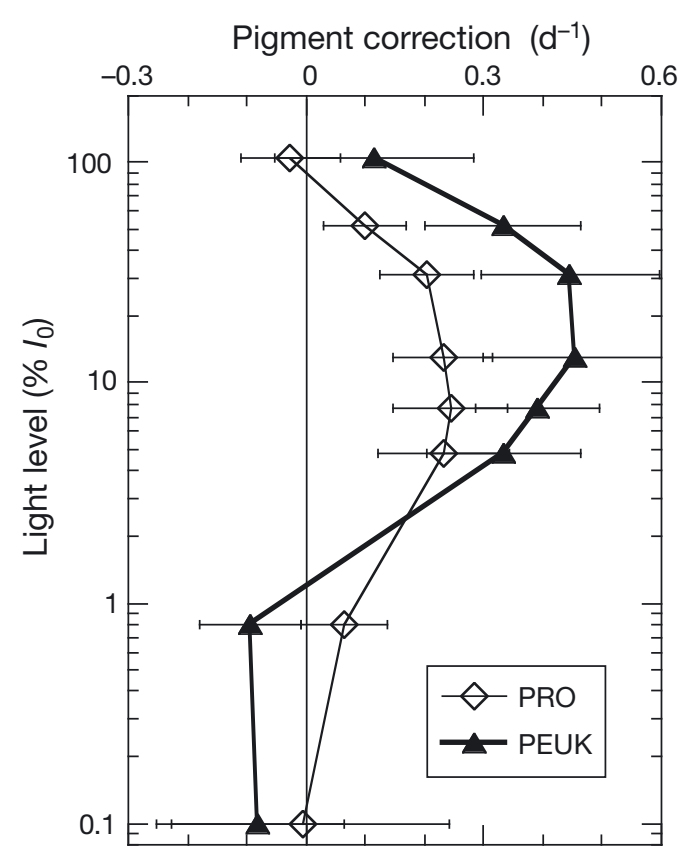

Fig. 6. Mean light-depth profiles of chl a corrections for Prochlorococcus (PRO) and photosynthetic eukaryotic cells (PEuk) in the equatorial Pacific region. Corrections are measured rates of change of cellular 'red' fluorescence as determined from flow cytometric analyses in experimental bottles incubated for $24 \mathrm{~h}$. Error bars represent \pm SD for 16 determinations at each light depth. $I_{0}$ : surface irradiance

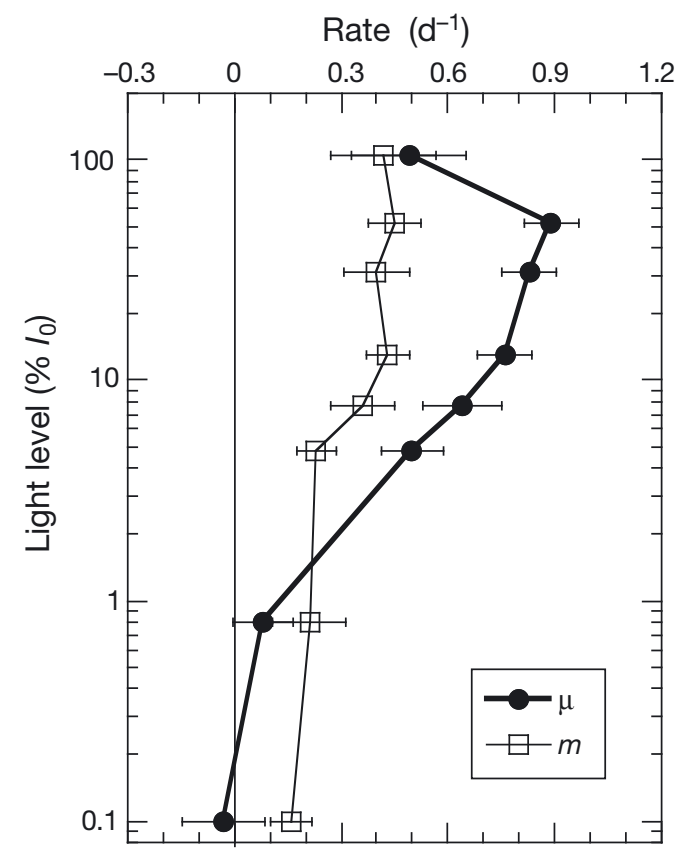

Fig. 7. Mean pigmented-corrected rates of phytoplankton growth $(\mu)$ and microzooplankton grazing $(m)$ in the equatorial Pacific region. Error bars are $95 \%$ confidence limits for experiments conducted at 16 stations (Fig. 1). $I_{0}$ : surface irradiance
In areas of the euphotic zone where experiments overlap, the present results are also consistent with previous rate estimates from the equatorial Pacific. For example, our mean $( \pm \mathrm{SD}, \mathrm{n}=48)$ rate estimate for phytoplankton growth in the upper euphotic zone, excluding the anomalous surface values, is $0.83 \pm$ $0.16 \mathrm{~d}^{-1}$, compared with $0.90 \pm 0.29 \mathrm{~d}^{-1}(\mathrm{n}=28)$ from the EqPac studies at $140^{\circ} \mathrm{W}$ (Landry et al. 1995a, Verity et al. 1996) and $0.76 \pm 0.26 \mathrm{~d}^{-1}(\mathrm{n}=4)$ for the EBENE experiments at $180^{\circ}$ (Landry et al. 2003). The growth rate estimates of Chavez et al. (1996) are substantially higher $\left(1.14 \pm 0.15 \mathrm{~d}^{-1}, \mathrm{n}=13\right)$ but are probably confounded with pigment artifacts (see below). Previous studies have also shown decreasing growth rates with decreasing light levels in the mid-euphotic zone, with crude 2- or 3-depth calculations of integrated rates to the $1 \%$ light level similar to ours $\left(0.54 \pm 0.19 \mathrm{~d}^{-1}\right)$, compared with $0.43 \pm 0.12 \mathrm{~d}^{-1}$ for EqPac El Niño conditions, $0.79 \pm 0.11 \mathrm{~d}^{-1}$ for EqPac normal upwelling and $0.52 \pm$ $0.19 \mathrm{~d}^{-1}$ for cold tongue conditions at $180^{\circ}$. These previous estimates are consistent with the inferences from depth-integrated contemporaneous estimates of ${ }^{14} \mathrm{C}$ primary production (Landry et al. 1997, 2003, LeBorgne \& Landry 2003). Our depth-integrated rate of microzooplankton grazing above the $1 \%$ light level $\left(0.32 \pm 0.13 \mathrm{~d}^{-1}\right)$ is less than that from EqPac $(0.50 \pm$ $\left.0.15 \mathrm{~d}^{-1}\right)$ but similar to EBENE $\left(0.35 \pm 0.14 \mathrm{~d}^{-1}\right)$, both of which have been shown to be consistent with balanced grazing of growth when mesozooplankton contributions and lateral advective fluxes are taken into consideration (Landry et al. 1997, LeBorgne \& Landry 2003). The upper mixed-layer grazing rates of $0.43 \pm 0.11 \mathrm{~d}^{-1}$ from Chavez et al. (1996) are also similar to ours for the same light-depth stratum (Fig. 7), though these authors suggested that their rates were significant underestimates because they did not balance their much higher growth estimates for the upper layer.

It should be clear from the present study that a growth-grazing balance for this region cannot be evaluated without knowledge of the depth distributions of rate processes in the euphotic zone, attention to pigment change artifacts and consideration of other losses. With regard to the mesozooplankton component of grazing, Décima et al. (2011) provided evidence of a substantial (approximately $2 \times$ ) increase in the biomass and grazing role of mesozooplankton in the HNLC equatorial Pacific region during the present study relative to that observed by EqPac in 1992. This is similar in magnitude and timing to the decadal increase in zooplankton that has been documented in monthly sampling events in the adjacent open-ocean ecosystem of the north Pacific subtropical gyre (Sheridan \& Landry 2004). During the present study, the increase in mesozooplankton grazing impact compensates for the lower proportions of phytoplankton 
growth consumed by microzooplankton relative to EqPac (Landry et al. 2011). From all studies to date, the HNLC equatorial Pacific is thus well characterized as a region of rapid phytoplankton growth rates and high grazing turnover (Landry et al. 1997, 2011).

Because the 2-treatment approach allowed us to run experiments at greater frequency and depth resolution than for previous studies, we are able to see that depth profiles in growth and grazing rates are robust and remarkably coherent among stations separated by great distances in the equatorial Pacific. This is surprising in part because the experimental data is based on calculated net rate differences between unreplicated bottles incubated for $24 \mathrm{~h}$, for which high variability or measurement errors would be expected. In fact, for this system, the variability in repeated measurements at different stations and independently collected and processed water samples from the same station seems to be unusually low compared with the rate signal. The resulting data are consistent with the general view of relatively uniform chemostat-like growth conditions in the HNLC equatorial Pacific (Frost \& Franzen 1992, Dugdale \& Wilkerson 1998, Dugdale et al. 2007), even at significant distances from the upwelling source of new nutrients and despite physical perturbations to the system on many scales (e.g. tropical instability waves, El Niño southern oscillation [ENSO] events). This may be a defining property of the behavior of this HNLC ecosystem, but it remains to be seen how it compares, for example, with oligotrophic central gyres of the oceans, which are also regarded as relatively stable and uniform.

Whereas the growth rates of phytoplankton from macronutrient-deficient waters are often seen to respond vigorously to deliberate nutrient additions in $24 \mathrm{~h}$ dilution experiments (e.g. Landry et al. 1998), this is not a characteristic observed in the HNLC equatorial Pacific, even when $\mathrm{Fe}$, the presumptive limiting resource, is provided (Landry et al. 1995a, 2003). From mesoscale Fe enrichment experiments, cellular growth rate and biomass of the ambient phytoplankton respond about $2 \mathrm{~d}$ after the Fe is added (Landry et al. $2000 \mathrm{a}, \mathrm{b})$. Of more concern on the time scale of our experiments is the rapid rate of change of cellular chl a content in responses to Fe addition (Behrenfeld et al. 1996, Coale et al. 1996). During the IronEx II experiments, for example, chl a increased relative to phytoplankton carbon at a rate of about $50 \%$ per day for the first 2 d after Fe fertilization (Landry et al. 2000a), which is approximately the mean net rate correction that we applied from flow cytometry measurements of our upper mixed-layer experiments (Fig. 6). Assuming that the responses of phytoplankton in our bottles parallel the observations of in situ fertilization experiments, the changes observed in cellular pigment con- tent could reflect low-level Fe contamination. We practiced trace-metal clean techniques in our cleaning, bottle handling and filling operations; however, we sampled seawater with the standard CTD rosette system with clean Niskin bottles, rather than an ultraclean system with GO-FLO bottles. Sanderson et al. (1995) have shown that such differences can lead to slight contamination of $\mathrm{Fe}$ and $\mathrm{Zn}$ in equatorial water samples, although $24 \mathrm{~h}$ rates of ${ }^{14} \mathrm{C}$-primary production were not significantly affected.

While Fe contamination is therefore a reasonable explanation for the general positive trend of cellular pigment corrections, light clearly affected the magnitude of the responses observed in some strata. At the shallower light depths, in particular, the approximately linear increase in pigment correction from 100 to $31 \%$ $I_{0}$ (Fig. 6) indicates that the mixed-layer samples collected before dawn have modified cellular pigments according to the mean light levels experienced during the day. In contrast, the relatively uniform and maximum corrections in the 3 to $31 \% I_{0}$ depth range suggest mainly an Fe effect; phytoplankton in this range were collected from the stratified portion of the euphotic zone and experienced mean incubation light levels similar to ambient light levels. Declining growth rate (Fe requirement) and increasing Fe concentration probably explains the diminishing correction observed in the deep euphotic zone (Fig. 6). Light intensities and spectral quality in our blue plastic incubators were most closely matched to the ambient environment at these deep light depths, so light adaptation effects would probably be minimal there.

As in the present study, Landry et al. (2003) corrected their growth rate estimates for measured changes in cellular chl a fluorescence. However, neither Landry et al. (1995a) nor Verity et al. (1996) noted cell pigment changes or corrected their EqPac growth estimates for such an effect. Chavez et al. (1996) also did not check or correct for change in cellular chl $a$, which is the likely explanation for their high growth rate estimates, similar to our uncorrected rates at upper mixed-layer light levels in Fig. 3. For the EqPac cruises, pigment adaptation effects may have been more subtle, or perhaps not present at all. These cruises are the only ones to have used a proper trace metal clean rosette for routine sample collection, in this case with GO-FLO bottles scrupulously prepared and maintained by trace metal geochemists from the Moss Landing Marine Laboratories. Even so, the most rigorous procedures for handling HNLC waters often leave unexplained nutrient drawdown or chl a increases in control samples incubated without Fe amendment (Banse 1991). It is thus not clear whether the consistent cell pigment response that we observed in our experiments is a phenomenon that distinguishes the HNLC 
equatorial Pacific region from other systems, or simply something that needs to be accounted for when interpreting the growth rates of Fe-limited phytoplankton in bottle incubations where inadvertent Fe contamination is possible, or commonplace.

\section{Growth and grazing in the deep euphotic zone}

Rate estimates of phytoplankton growth and microzooplankton grazing from dilution experiments are often strongly and linearly related (Furnas 1990, Strom \& Welschmeyer 1991, Latasa et al. 1997, McManus et al. 2007, Chen et al. 2009). This phenomenon is so well known that a recent study by Gutiérrez-Rodríguez et al. (2009) questioned whether it reflected an ecologically meaningful relationship or an artifact caused by the interdependence of the 2 rate parameters in the calculated dilution regressions. Their evidence supported the former explanation, at least for the system, Blanes Bay, where studies were conducted to evaluate these alternatives. Ecologically, the strong rate relationship can be interpreted as a close coupling of growth and loss processes among microbial and protistan components of the food web that can respond equally rapidly to variations in their resource/food environments. In addition, Strom $(2001,2002)$ suggested that growth and loss processes may be linked by the physical variable, light, which drives photosynthesis in the phytoplankton and may facilitate digestion of pigmented prey by their grazers. Whether light-aided digestion (Strom 2001) leads inevitably, however, to higher grazing rates is not straightforward. Under high-food circumstances, where the rate-limiting step in the feeding process may well be digestion rate, the mechanism should allow individual grazers to consume more biomass per unit time. These are circumstances, however, of saturated grazing, where the dilution assumption of linearity is probably violated. In the equatorial Pacific, as in the open ocean generally, the available evidence suggests that biomass-specific rates of feeding by microzooplankton are far below the level that would support maximum growth (Landry et al. 2000b, 2003). For these circumstances, feeding is more likely limited by encounter frequency with suitable prey (the dilution assumption) rather than vacuole turnover rate, although light-aided digestion could still enhance efficiency of growth achieved from a given amount of prey ingested, and thus positively affect consumer response at the population level. The present study does not elucidate potential light effects on grazer physiology or population growth. It is nonetheless important to keep in mind that light levels in the euphotic zone could act in some way to couple the dynamics of phototrophic and phagotrophic populations.
To test whether the strongly correlated growth and grazing rates from dilution experiments could be made to dissociate, Gutiérrez-Rodríguez et al. (2009) used light level as an experimental tool to manipulate growth rate independent of grazing. This is interestingly the same logic that led us to hypothesize that the base of the euphotic zone would be a place where growth and grazing might naturally decouple in ocean ecosystems. Photon flux is greatly diminished in the lower euphotic zone; in the present study it is 1 to 2 orders of magnitude lower than the level at which light becomes demonstrably limiting to phytoplankton growth in the overlying waters (Figs. $2 \& 6$ ). However, the food resources for protistan grazers do not decline as rapidly with depth. For example, chlorophyll values were approximately constant on average from the surface to the $1 \%$ light level, only decreasing by half at the $0.1 \%$ light depth (Fig. 2). More importantly, since chl a content of phytoplankton varies with depth, mean cell abundances and biomass concentrations of bacteria, total autotrophs and heterotrophic protists from flow cytometric and microscopical analyses were all only lower by a factor of 2 or 3 in the deep euphotic zone compared with the upper mixed layer (Taylor et al. 2011). Thus, the food environment and the density of grazers remain at levels adequate for lower, but still substantial, rates of grazing in the deep euphotic zone, where the light for photosynthesis sharply declines and the balance of processes shifts from net positive to net negative growth.

In terms of our chlorophyll-based rate estimates, the net negative growth of phytoplankton in the deep euphotic zone implies that $6.8 \%$ on average of the excess production of chl a from the upper euphotic zone must enter the deeper layer as a grazing subsidy. Assuming that cells increase their cellular chl a contents as they sink to darker and deeper water, this probably overestimates by about a factor of 2 the percentage of upper water carbon production needed to offset grazing in the lower euphotic zone. Flux of this small magnitude could be readily accomplished by a slow rain of larger cells from the upper layers, or smaller cells associated with aggregates (Richardson \& Jackson 2007). In addition, however, Walsh et al. (1997) have suggested that meridional flows in equatorial circulation are important in returning excess particle production that diverges away from the equator in surface waters back towards the equator in the depth range of the deep euphotic zone. Thus, lateral advective flows in opposite directions in upper and lower depth strata link the euphotic zones for several degrees on either side of the equator.

In terms of in situ production, our measured negligible rate of phytoplankton cell growth in the deep euphotic zone does not mean that photosynthesis is also virtually nonexistent there. For the equatorial 
Pacific, Barber et al. (1996) have shown that the 0.1 to $1 \%$ light-depth stratum (nominally 80 to $120 \mathrm{~m}$ ) accounts on average for carbon uptake of $\sim 6 \mathrm{mmol} \mathrm{C}$ $\mathrm{m}^{-2} \mathrm{~d}^{-1}$, typically 5 to $10 \%$ of total production for the euphotic zone. Karl et al. (1996) have also reported a similar fraction of total primary production in the deepest third (>100 m) of the euphotic zone in the subtropical north Pacific. Nonetheless, chlorophyll-specific rates of carbon uptake are greatly reduced at depth (Barber et al. 1996), and much or most of this uptake may go to offsetting cell maintenance costs rather than new cell growth. The excess of grazing losses over cell growth in the deep euphotic layer implies that this is probably a zone of phytoplankton degradation and decay. This is consistent with contemporaneous measurements of high net rates of biogenic Si dissolution (Krause et al. 2011) and greatly reduced ratios of chl a content to cell biovolume (Taylor et al. 2011) in the deep euphotic layer.

In the present study, the deep euphotic zone (light depths $<0.8 \%$ surface irradiance) of the equatorial Pacific accounted for $25.4 \pm 8.4 \%$ of the total euphotic zone chl $a, 0.5 \pm 7.8 \%$ of depth-integrated phytoplankton growth, and $12.7 \pm 7.2 \%$ of depth-integrated microzooplankton grazing on phytoplankton. Viewed either as raw rate estimates (Fig. 3) or as rates corrected for changes in cellular fluorescence (Fig. 7), our experiments support the hypothesis that growth and grazing processes can decouple significantly under low light conditions at the base of the euphotic zone. They also provide field evidence that is consistent with the theoretical analysis and experimental manipulations of Gutiérrez-Rodríguez et al. (2009). It is clear from our results that chlorophyll-based assessments of phytoplankton dynamics from dilution experiments incubated at upper to mideuphotic light levels can, and might often, substantially underestimate the total grazing impact of microzooplankton. In the present case, microherbivores consumed $51 \%$ of chlorophyll in the upper euphotic stratum, but $69 \%$ on a depthintegrated basis for the full euphotic zone (Fig. 7). This difference can be important in studies where the goal is to quantify and account for the alternative fates of primary production. Perhaps more important than getting the magnitude of the microzooplankton grazing impact correct, however, the deep euphotic zone is a place where phagotrophic protists and other microbes have their final opportunity to rework and modify sinking particulates as they leave the euphotic zone. The substantial excess of grazing over growth processes in this stratum suggests that the potential of phagotrophic protists to transform export fluxes may be quite large if mean particle residence times in the deep layer extend over several to many days. We thus might develop a better understanding of microbial rates and roles in particle transformation and export processes if this portion of the euphotic zone were more consistently integrated into experimental studies of plankton dynamics and biogeochemical cycling.

Acknowledgements. This study was supported by subcontracts to Scripps Institution of Oceanography and the University of Hawaii at Manoa from National Science Foundation Biocomplexity grant OCE 03-22074 (awarded to D. Nelson, Oregon State University), and by Ministry of Land, Transport and Maritime Affairs of South Korea (PM54903). We gratefully acknowledge the captain and crew of RV 'Roger Revelle' and all of our shipmates and colleagues whose efforts facilitated and contributed to our results.

\section{LITERATURE CITED}

Balch WM, Poulton AJ, Drapeau DT, Bowler BC, Windecker LA, Booth ES (2011) Zonal and meridional patterns of phytoplankton biomass and carbon fixation in the equatorial Pacific Ocean, between $110^{\circ} \mathrm{W}$ and $140^{\circ} \mathrm{W}$. Deep-Sea Res II 58 (in press) doi:10.1016/j.dsr2.2010.08.004

Banse K (1991) Rates of phytoplankton cell division in the field and in iron enrichment experiments. Limnol Oceanogr 36:1886-1898

- Barber RT, Sanderson MP, Lindley ST, Chai F and others (1996) Primary productivity and its regulation in the equatorial Pacific during and following the 1991-1992 El Niño. Deep-Sea Res II 43:933-970

Behrenfeld MJ, Bale AJ, Kolber ZS, Aiken J, Falkowski PG (1996) Confirmation of iron limitation of phytoplankton photosynthesis in the Equatorial Pacific Ocean. Nature 383:508-511

Calbet A, Landry MR (2004) Phytoplankton growth, microzooplankton grazing and carbon cycling in marine systems. Limnol Oceanogr 49:51-57

Campbell L, Vaulot D (1993) Photosynthetic community structure in the subtropical Pacific Ocean near Hawaii (Station Aloha). Deep-Sea Res I 40:2043-2060

Chavez FP, Buck KR, Service SK, Newton J, Barber RT (1996) Phytoplankton variability in the central and eastern tropical Pacific. Deep-Sea Res II 43:835-870

Chen B, Liu H, Landry MR, Dai M, Huang B, Sun J (2009) Close coupling between phytoplankton growth and microzooplankton grazing rates in the western South China Sea. Limnol Oceanogr 54:1084-1097

> Coale KH, Johnson KS, Fitzwater SE, Gordon RM and others (1996) A massive phytoplankton bloom induced by an ecosystem-scale iron fertilization experiment in the equatorial Pacific Ocean. Nature 383:495-501

Décima M, Landry MR, Rykaczewski R (2011) Broad-scale patterns in mesozooplankton biomass and grazing in the eastern equatorial Pacific. Deep-Sea Res II 58 (in press) doi:10.1016/j.dsr2.2010.08.006

Dugdale RC, Wilkerson FP (1998) Silicate regulation of new production in the equatorial Pacific upwelling. Nature 391:270-273

$>$ Dugdale RC, Wilkerson FP, Chai F, Feely R (2007) Size-fractionated nitrogen uptake measurements in the equatorial Pacific and confirmation of the low Si-high-nitrate lowchlorophyll condition. Global Biogeochem Cycles 21: GB2005. doi:10.1029/2006GB002722

> Feely RA, Boutin J, Cosca CE, Dandonneau Y and others (2002) Seasonal and interannual variability of $\mathrm{CO}_{2}$ in the equatorial Pacific. Deep-Sea Res II 49:2443-2469

Frost BW, Franzen NC (1992) Grazing and iron limitation in 
the control of phytoplankton stock and nutrient concentration: a chemostat analogue of the Pacific equatorial upwelling zone. Mar Ecol Prog Ser 83:291-303

Furnas MJ (1990) In situ growth rates of marine phytoplankton: approaches to measurement, community and species growth rates. J Plankton Res 12:1117-1151

Gutiérrez-Rodríguez A, Latasa M, Mourre B, Laws EA (2009) Coupling between phytoplankton growth and microzooplankton grazing in dilution experiments: potential artefacts. Mar Ecol Prog Ser 383:1-9

Karl DM, Christian JR, Dore JE, Hebel DV, Letelier RM, Tupas LM, Winn CD (1996) Seasonal and interannual variability in primary production and particle flux at Station ALOHA. Deep-Sea Res II 43:539-568

Krause JW, Nelson DM, Brzezinski MA (2011) Biogenic silica production and the diatom contribution to primary and nitrate uptake in the eastern equatorial Pacific Ocean. DeepSea Res II 58 (in press) doi:10.1016/j.dsr2.2010.08.010

Landry MR (2009) Grazing processes and secondary production in the Arabian Sea: a simple food web synthesis with measurement constraints. In: Wiggert JD, Hood RR, Naqvi SWA, Brink KH, Smith SL (eds) Indian Ocean biogeochemical processes and ecological variability. AGU Monograph. American Geophysical Union, Washington, DC, p 133-146

Landry MR, Calbet C (2004) Microzooplankton production in the oceans. ICES J Mar Sci 61:501-507

> Landry MR, Hassett RP (1982) Estimating the grazing impact of marine microzooplankton. Mar Biol 67:283-288

> Landry MR, Haas LW, Fagerness VL (1984) Dynamics of microplankton communities: experiments in Kaneohe Bay, Hawaii. Mar Ecol Prog Ser 16:127-133

Landry MR, Constantinou J, Kirshtein J (1995a) Microzooplankton grazing in the central equatorial Pacific during February and August 1992. Deep-Sea Res II 42:657-671

Landry MR, Kirshtein J, Constantinou J (1995b) A refined dilution technique for measuring the community grazing impact of microzooplankton, with experimental tests in the central equatorial Pacific. Mar Ecol Prog Ser 120: $53-63$

> Landry MR, Barber RT, Bidigare RR, Chai F and others (1997) Iron and grazing constraints on primary production in the central equatorial Pacific: an EqPac synthesis. Limnol Oceanogr 42:405-418

Landry MR, Brown SL, Campbell L, Constantinou J, Liu H (1998) Spatial patterns in phytoplankton growth and microzooplankton grazing in the Arabian Sea during monsoon forcing. Deep-Sea Res II 45:2353-2368

Landry MR, Ondrusek ME, Tanner SJ, Brown SL and others (2000a) Biological response to iron fertilization in the eastern equatorial Pacific (IronEx II). I. Microplankton community abundances and biomass. Mar Ecol Prog Ser 201:27-42

Landry MR, Constantinou J, Latasa M, Brown SL, Bidigare RR, Ondrusek ME (2000b) Biological response to iron fertilization in the eastern equatorial Pacific (IronEx II). III. Dynamics of phytoplankton growth and microzooplankton grazing. Mar Ecol Prog Ser 201:57-72

Landry MR, Brown SL, Neveux J, Dupouy C, Blanchot J, Christensen S, Bidigare RR (2003) Phytoplankton growth and microzooplankton grazing in high-nutrient, lowchlorophyll waters of the equatorial Pacific: community and taxon-specific rate assessments from pigment and flow cytometric analyses. J Geophys Res 108(C12):8142 doi:10.1029/2000JC000744
Landry MR, Brown SL, Rii YM, Selph KE, Bidigare RR, Yang EJ, Simmons MP (2008) Depth-stratified phytoplankton dynamics in Cyclone Opal, a subtropical mesoscale eddy. Deep-Sea Res II 55:1348-1359

Landry MR, Selph KE, Taylor AG, Décima M, Balch WM, Bidigare RR (2011) Phytoplankton growth, grazing and production balances in the HNLC equatorial Pacific. Deep-Sea Res II 58 (in press) doi:10.1016/j.dsr2.2010. 08. 011

Latasa M, Landry MR, Schülter L, Bidigare RR (1997) Pigment-specific growth and grazing rates of phytoplankton in the central equatorial Pacific. Limnol Oceanogr 42: 289-298

> Le Borgne R, Landry MR (2003) EBENE: A JGOFS investigation of plankton variability and trophic interactions in the equatorial Pacific (180). J Geophys Res 108(C12):8136 doi:101029/2000JC001252

> McManus GB, Costas BA, Dam HG, Lopes RM, Gaeta SA, Susini SM, Rosetta CH (2007) Microzooplankton grazing of phytoplankton in a tropical upwelling region. Hydrobiologia 575:69-81

> Monger BC, Landry MR (1993) Flow cytometric analysis of marine bacteria with Hoechst 33342. Appl Environ Microbiol 59:905-911

> Richardson TL, Jackson GA (2007) Small phytoplankton and carbon export from the surface ocean. Science 315 : $838-840$

Sanderson MP, Hunter CN, Fitzwater SF, Gordon RM, Barber RT (1995) Primary productivity and trace-metal contamination measurements from a clean rosette system versus ultra-clean Go-Flo bottles. Deep-Sea Res II 42:431-440

> Selph KE, Landry MR, Allen CB, Calbet A, Christiansen S, Bidigare RR (2001) Microbial community composition and growth dynamics in the Antarctic Polar Front and seasonal ice zone during late spring of 1997. Deep-Sea Res II 48: 4059-4080

Selph KE, Landry MR, Taylor AG, Yang EJ and others (2011) Spatially-resolved taxon-specific phytoplankton production and grazing dynamics in relation to iron distributions in the equatorial Pacific between 110 and $140^{\circ} \mathrm{W}$. DeepSea Res II 58 (in press) doi:10.1016/j.dsr2.2010.08.014

Sheridan CC, Landry MR (2004) A nine-year increasing trend in mesozooplankton biomass at the Hawaii Ocean Timeseries Station ALOHA. ICES J Mar Sci 61:457-463

Strom SL (2001) Light-aided digestion, grazing and growth in herbivorous protists. Aquat Microb Ecol 23:253-261

Strom SL (2002) Novel interactions between phytoplankton and microzooplankton: their influence on the coupling between growth and grazing rates in the sea. Hydrobiologia 480:41-54

Strom SL, Welschmeyer NA (1991) Pigment-specific rates of phytoplankton growth and microzooplankton grazing in the open subarctic Pacific Ocean. Limnol Oceanogr 36: $50-63$

Taylor AG, Landry MR, Selph KE, Yang EJ (2011) Biomass, size structure and depth distributions of the microbial community in the eastern equatorial Pacific. Deep-Sea Res II 58 (in press) doi:10.1016/j.dsr2.2010.08.017

Verity PG, Stoecker DK, Sieracki ME, Nelson JR (1996) Microzooplankton grazing of primary production in the equatorial Pacific. Deep-Sea Res II 43:1227-1255

Walsh ID, Gardner WD, Richardson MJ, Chung SP, Plattner CA, Asper VL (1997) Particle dynamics as controlled by the flow field of the eastern equatorial Pacific. Deep-Sea Res 44:2025-2047 